\title{
Science as a Constituent of University Education
}

by

A. B. PIPPARD

Cavendish Laboratory, Cambridge
Professor Pippard, a member of the Swann working group on scientific manpower, argues for a pattern of university education based on two years of general study and further years of specialization.
Within the next few days the new academic year will begin, and I shall be facing again an audience of some 250 freshmen, to tell them of Newton's laws of motion and their consequences. Three years from now they expect to go down with honours degrees, whose standard is nowadays so elevated as to leave me little choice but to get down to business at a pace that would have made me sit up in my own student days; though I had the advantage of being taught at school very much better than are most students. This picture is not peculiar to Cambridge (which indeed still attempts a broad scientific education), but is typical of the whole country. The rigid three year course and the tradition of deep learning for the intellectual élite constrain secondary and university science education into a strait-jacket of specialism which is increasingly seen, especially from outside, as menacing our future development, industrial and social. So long as the standards of the only reputable degree are pegged to the international professional qualification (say a master's degree at a major American university), we cannot avoid training a greater number of specialists than are needed as such, and overlooking the real needs of the vast number of students who would be happier, better educated and more useful in society if they had had a more general course. Moreover, the standards we find ourselves promoting can only be achieved in the allotted time by early specialization at school, even though we have no hope of producing schoolteachers in the quantity or of the quality that would justify this practice.

\section{Educational Reality}

I do not see clearly any way of improving the situation by the sort of gradual measures that are most generally acceptable, but it may be possible if we have some idea of what we are aiming at, so that we can take advantage of every opportunity that occurs. I therefore propose to outline my personal view of what would be an improved pattern of university education, substantially different from our present pattern, though with marked affinities with what has grown up in America. It involves the attempt to make an educational reality of what most of us assent to without hesitation: that science is more than a specialist expertise, it is indeed an inescapable part of an "advanced" culture, and its acceptance as such is essential to social health. It is my ideal, therefore, not to attempt to produce more science teachers in schools but, quite the reverse, to make them in the long term almost unnecessary. It should be possible for every schoolmaster at a pinch to take a class in science, just as he takes a class in English-mugging up the set book, perhaps, but able to do so with a fair chance of success because what he reads is compatible with his cultural background. At the same time, the general scientific education which could bring this to pass would not just produce schoolmasters, but would provide a solid background for careers in government and all sections of industry, except the research laboratories and specifically technical posts.

Most attempts to provide general courses in science at universities have instituted them as an alternative, in parallel with the conventional specialist courses. It is difficult to believe that they can thrive in these circumstances, and indeed they do not seem to-most students feel the pull of the more demanding, intellectually more "respectable", specialism, and university teachers find it hard to maintain enthusiasm for the general courses for long enough to create a tradition of attractiveness for the brighter students. I propose therefore, as the only arrangement likely to succeed, that all students concerned with science or technology should spend two years on a course built around a general syllabus, specifically designed to educate rather than impart professional skill. I shall say a little more about the content of this course later. The rest of the time might be devoted to a rather deeper study of a number of more specialized topics in mathematics or science, though it would be better still if most students took courses in economics or other social studies. But, however the courses were compiled, it should be the overall aim to range widely, and only for a small fraction of the course to indulge in the intense intellectual activity that science students have to face at present. This is not a proposal to throw academic standards overboard, but only to make no greater demands at this stage on science students than on arts students, in the hope that more of the latter would be attracted by the intrinsic interest of science into basing their education on it, and at the same time would have enough time to study and to enjoy university life simultaneously.

At the end of two years would come the examination for the bachelor's degree, and here many students would finish their university course. Those who wished to receive specialized education, or training for a specific career, would compete for places, and aim for master's degrees, at any institution that offered what they wanted. Thus one might picture advanced courses, lasting two years, in any one pure science at ten or twenty different universities, while other universities, especially the former colleges of advanced technology, would offer general and special engineering degrees, and others would cater for medical students, teachers and so on. The idea would be to replace three years for all by two years for all and four for some, with mobility at the end of the second year. By making 
entry to the master's courses competitive it would be possible for government to control in a general way the output of specialists in various fields. If half the students went on to the master's degree the average university course would still be three years, so that no extra new building would be needed and student grants would total the same, with the same numbers entering as at present. Perhaps the present "wastage" rate, though not inordinately high, would be substantially reduced.

For the proposed scheme to work efficiently it would be necessary to restrict the number of universities offering specialist courses in any one subject. Physics, for example, should be taught at the present honours level by a team whose research interests are well diversified, and for this purpose between twenty and thirty staff members are desirable; with this size of department, and with help from the considerable body of research students whom they should be supervising, there is no reason why the master's class should be less than eighty. But with this as a typical class size, there need not be more than fifteen classes in the country to produce as many specialists as are needed. One would expect most universities, then, to have only a small team of physicists, to take part in the general courses, and-this is most important-to undertake research. If the staff were chosen chiefly within a limited specialism, a team of ten could well be the leading research team in their own field, and could expect to attract good research students, especially from those who took their bachelor's degree there, and would enjoy returning after a master's course elsewhere. An arrangement along these lines would permit all universities to run advanced courses and diversified research programmes in a limited number of fields, without debarring them from building up more specialized research teams in other subjects. It might be hoped that critical control of research grants by central committees, formed principally of university representatives, would lead to a higher overall standard than is attained by the present somewhat haphazard free for all; but the problems involved in encouraging centres of excellence and, perhaps even more important, discouraging mediocre research are too complex to discuss here.

\section{Organizational Problems}

Without doubt this proposed scheme involves many organizational problems, some perhaps so serious as to make it unworkable, but I see no value in giving up the attempt to promote radical reform if the alternative is acceptance of the present system as the best we can hope for. At any rate, one at least of the fundamental problems is one which I am confident can be solved in many different ways, and that is the problem of devising a general course in science. Many scientists bolieve that the only way to understand what science is really about is to learn it thoroughly, but surely this is misplaced professional pride. In particular, the hours of drudgery (or perhaps enjoyment) in practical classes could be enormously reduced, for they often involve repetitious practice in a narrow gamut of tcchniques which are only of professional value. And the same goes for much of the problem solving that is rightly central in specialist courses in mathematics and physics. These are things that could be eliminated from a general course, with a transfer of emphasis to quite other matters.

The content of the course, for example, should include a world-picture as seen by cosmologists, physicists, chemists, biologists, psychologists and others, without necessarily any detailed discussion of how it was built up. Various special topics might be selected for closer examination to exhibit typical examples of scientific reasoning (for example, the mapping of the solar system, natural selection, Mendelism, valency, radioactivity), and these need not involve elaborate chains of argument-it would be a mistake to concentrate too much (following so many philosophers of science) on the rather atypical science that physics has become, with its long mathematical deductions from well-tried postulates.

A second, and equally important, strand in the development of the argument would explore the relationship between pure science and technology and the social implications of engineering, agricultural science, medicine, drugs and so on. Even though one might not elect to give lecture courses on the moral problems involved, there is no lack of books and articles from which a thought provoking reading list could be compiled.

\section{Everyday Life}

In all these facets of the course the intellectual attitudes inculcated should be those which are also relevant to everyday life. For example, genetics might be made an excuse for teaching the use of statistics and recognition of its abuse. Part of the discussion of technology could deal with the logical organization of complex tasks, and there can be little doubt about the value of an extended treatment of modern computers and their capabilities. And there is no lack of material in human physiology to exhibit scientific methods of investigation while simultaneously teaching the student something about himself.

Having started, one could go on indefinitely, and everyone would have different ideas about how to get across the meaning of science in the modern world. Perhaps what is needed is a publisher to commission a series of texts from an enthusiastic team; surely it would sell well, even before it became the basis of systematic teaching. But this is a detail-it is no more than one way of helping our society to decide whether a reorganization of the educational system along these, or other, lines is called for, and, if so, to see how to put it into practice.

In all this I have concentrated on the university course, although it might be argued that it is more logical to start with the schools, especially as they are more centrally controlled and more capable of coherent reform. I cannot see, however, that real liberalization of science teaching in schools can come without first creating a new generation of schoolmasters. Moreover, I see no serious harm, for the moment, in science being introduced as a collection of specialized ideas and techniques, provided a broader view is adopted later. After all, the study of classics makes grammar the prelude to a genuinely humane education, and science might well attempt a similar pattern. But, when all is said and done, the important thing is to set up a not impossible, even if limited, objective and to aim to achieve something like it as a first step, recognizing that this is indeed only one stage in what should be a continuing evolutionary process. 